\title{
Effect of Porphyrin Molecular Structure on Water Splitting Activity of a $\mathrm{KTaO}_{3}$ Photocatalyst
}

\author{
Hidehisa Hagiwara ${ }^{1,2, *}$, Kohei Higashi ${ }^{1}$, Motonori Watanabe ${ }^{2}$, Ryota Kakigi ${ }^{1}$, Shintaro Ida ${ }^{1,2}$ \\ and Tatsumi Ishihara 1,2 \\ 1 Department of Applied Chemistry, Kyushu University, Motooka 744, Nishi-ku, Fukuoka 819-0395, Japan; \\ 2FS14047G@s.kyushu-u.ac.jp (K.H.); mr.r.kacky1213@gmail.com (R.K.); s-ida@cstf.kyushu-u.ac.jp (S.I.); \\ ishihara@cstf.kyushu-u.ac.jp (T.I.) \\ 2 International Institute for Carbon-Neutral Energy Research (I2CNER), Motooka 744, Nishi-ku, \\ Fukuoka 819-0395, Japan; mwata@i2cner.kyushu-u.ac.jp \\ * Correspondence: h.hagiwara@cstf.kyushu-u.ac.jp; Tel.: +81-92-8026-709; Fax: +81-92-8026-713 \\ Academic Editor: Bunsho Ohtani \\ Received: 15 January 2016; Accepted: 22 February 2016; Published: 10 March 2016
}

\begin{abstract}
Photocatalytic water splitting is one of the ideal methods for solving the global energy crisis and its associated environmental problems. In this study, the effect of altering the molecular structure of porphyrins was investigated to improve the water splitting activity of $\mathrm{Zr}$-doped $\mathrm{KTaO}_{3}\left(\mathrm{KTa}(\mathrm{Zr}) \mathrm{O}_{3}\right)$ modified with porphyrin dyes. UV-vis spectra indicated that porphyrins with long alkoxy chains tended to form well-developed $\mathrm{H}$-aggregates on the $\mathrm{KTa}(\mathrm{Zr}) \mathrm{O}_{3}$ surface. The photocatalytic activity of Pt-loaded $\mathrm{KTa}(\mathrm{Zr}) \mathrm{O}_{3}$ was improved by using porphyrins with longer alkoxy chains because of the improvement in the charge migration between porphyrin dye molecules. While the charge transfer between the inorganic semiconductor and porphyrin dye interface is important, it was found that the formation of $H$-aggregation was more effective in improving the water splitting activity of the porphyrin-modified photocatalysts.
\end{abstract}

Keywords: water splitting; alkali tantalate; porphyrin; photocatalyst; hydrogen

\section{Introduction}

Photocatalytic water splitting is one of the most promising strategies for renewable and clean production of hydrogen. This method of hydrogen production has attracted much attention not only for the conversion of light energy but also from a scientific viewpoint, because photocatalytic water splitting is regarded as an artificial photosynthetic system. In photosynthesis, two photons are required to facilitate NADPH synthesis from $\mathrm{NADP}^{+}$and water [1]. This two-step excitation process, the so-called "Z-scheme", has been widely studied in both fundamental and applied fields of research [2-5]. In the past decade, various systems capable of Z-scheme water splitting (Figure 1b), such as $\mathrm{Pt}$ or $\mathrm{Ru} / \mathrm{SrTiO}_{3}: \mathrm{Rh}-\mathrm{Fe}^{3+} / \mathrm{Fe}^{2+}-\mathrm{WO}_{3}, \mathrm{BiVO}_{4}$, or $\mathrm{Bi}_{2} \mathrm{MoO}_{6}[6,7], \mathrm{Pt} / \mathrm{TaON}-\mathrm{IO}_{3}{ }^{-} / \mathrm{I}^{-}-\mathrm{PtO} \times \mathrm{WO}_{3}$ or $\mathrm{RuO}_{2} / \mathrm{TaON}$ [8,9], Pt/ $\mathrm{ZrO}_{2} / \mathrm{TaON}-\mathrm{IO}_{3}{ }^{-} / \mathrm{I}^{-}-\mathrm{Ir} / \mathrm{TiO}_{2} / \mathrm{Ta}_{3} \mathrm{~N}_{5}$ or $\mathrm{RuO}_{2} / \mathrm{TaON}$ [10,11], and other systems [12-15], have been reported. Our research group has also reported Z-scheme water splitting using porphyrin-dye-modified inorganic semiconductors, such as $\mathrm{KTa}(\mathrm{Zr}) \mathrm{O}_{3}$ [16-18], GaN:ZnO [19] and TaON [20]. In these dye-modified photocatalysts, the dyes used for modification improve the utilization efficiency of visible light and increase the charge separation lifetime owing to the electron transfer between the excited inorganic semiconductors and the dyes, as shown in Figure 1c. In our previous results, it was found that 5,10,15,20-tetrakis(tetraphenyl)porphyrin-Cr(III) chloride ( $\mathrm{Cr}-\mathrm{TPPCl}$, Dye 1 in this study) had a positive effect on the photocatalytic activity of $\mathrm{KTa}(\mathrm{Zr}) \mathrm{O}_{3}$ for overall water splitting [17]. $\mathrm{Cr}$-TPPCl formed aggregates on the surface of $\mathrm{KTa}(\mathrm{Zr}) \mathrm{O}_{3}$, which is similar to the structure of the chlorophyll special pair in the naturally occurring photosynthetic reaction center [21]. 
Thus, we have an interest in the relation between the aggregation states of porphyrins and their effects on the photocatalytic activity of the $\mathrm{Cr}-\mathrm{TPPCl} / \mathrm{KTa}(\mathrm{Zr}) \mathrm{O}_{3}$ system. Therefore, in this study, we have synthesized various porphyrins that contain chromium-coordinated porphyrin structures with different alkoxy chain lengths and used these compounds as modification dyes for the $\mathrm{KTa}(\mathrm{Zr}) \mathrm{O}_{3}$ photocatalyst. The aggregation states of the porphyrins were investigated by using UV-vis absorption spectroscopy; photocatalytic water splitting on $\mathrm{KTa}(\mathrm{Zr}) \mathrm{O}_{3}$ modified with various porphyrins was also demonstrated.

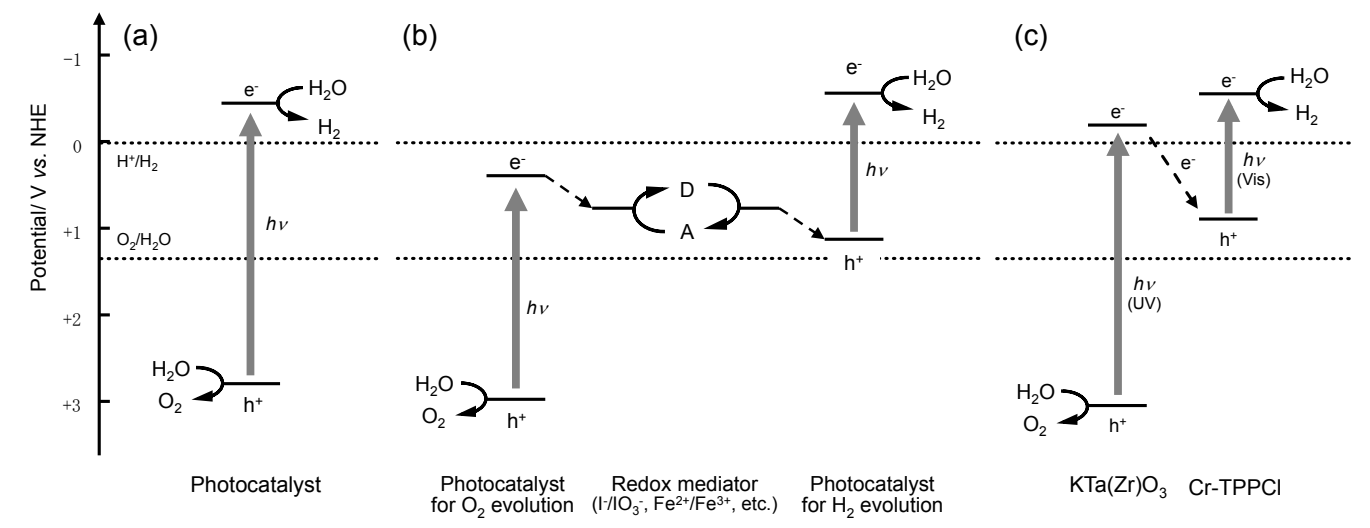

Figure 1. Various heterogeneous photocatalyst systems for water splitting reaction. (a) A one-photon system; (b) the Z-scheme system; and (c) the Cr-TPPCl-modified $\mathrm{KTa}(\mathrm{Zr}) \mathrm{O}_{3}$ system.

\section{Results and Discussion}

Various porphyrins (Figure 2), including 5,10,15,20-tetrakis(tetraphenyl)porphyrin-Cr(III) chloride (Dye 1), 5,10,15,20-tetrakis(4-methoxyphenyl)porphyrin-Cr(III) chloride (Dye 2), 5,10,15,20-tetrakis(4-(propoxy)phenyl)porphyrin-Cr(III) chloride (Dye 3), 5,10,15,20-tetrakis (4-(hexyloxy) phenyl)porphyrin-Cr(III) chloride (Dye 4), 5,10,15,20-tetrakis(4-(dodecyloxy)phenyl) porphyrin-Cr(III) chloride (Dye 5) and 5,10,15,20-tetrakis(4-(hexadecyloxy)phenyl)porphyrin-Cr(III) chloride (Dye 6), were used to investigate the effect of molecular structure on the photocatalytic activity of $\mathrm{KTa}(\mathrm{Zr}) \mathrm{O}_{3}$. The ${ }^{1} \mathrm{H}$ NMR, ${ }^{13} \mathrm{C}$ NMR and CSI-MS spectra of the porphyrins are summarized in the Supplementary Materials (Figures S1-S9). From these results, we could confirm that the porphyrins were successfully synthesized.
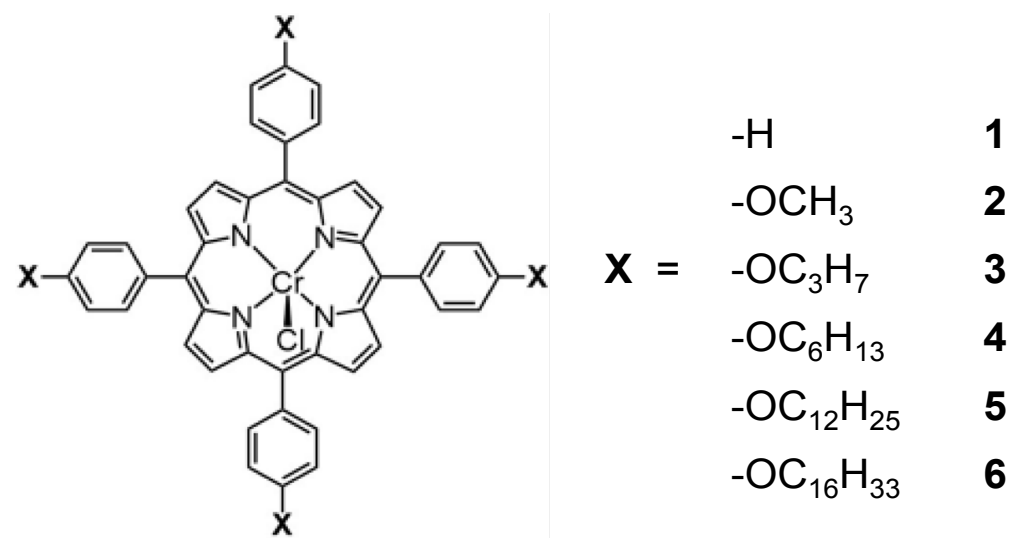

Figure 2. Molecular structures of the porphyrin dyes used for the modification of $\mathrm{KTa}(\mathrm{Zr}) \mathrm{O}_{3}$.

Figure 3 shows the UV-vis spectra of the synthesized porphyrins dissolved in $\mathrm{CH}_{2} \mathrm{Cl}_{2}$. In all spectra, the Soret and Q-band absorptions, which are typical porphyrin absorption bands, were 
observed at 450 and 560-610 nm, respectively. Compared with the spectrum of Dye 1 (Figure 3a), the absorption peaks of Dyes 2-6 were slightly shifted to longer wavelengths because of electron donation from alkoxy groups. The peak intensities in the absorption spectra of Dyes 2-6 appeared at the same positions; thus, it appears that the porphyrin dyes 2-6 exhibit similar energy states. To investigate the energy states of the porphyrin dyes, cyclic voltammetry was performed (Figure S10). The first oxidation-reduction potential was observed at $-1.48 \mathrm{~V}$ (vs. $\mathrm{Ag} / \mathrm{Ag}^{+}$) for Dye 1, while the potentials for Dyes 2-6 were observed at $-1.51 \mathrm{~V}$ (vs. $\mathrm{Ag} / \mathrm{Ag}^{+}$). The small difference between Dye 1 and the other dyes was also attributed to electron donation from the alkoxy groups. The ability of the alkoxy chain to donate electron density to the porphyrin ring appears to be similar, regardless of the length of the chain.
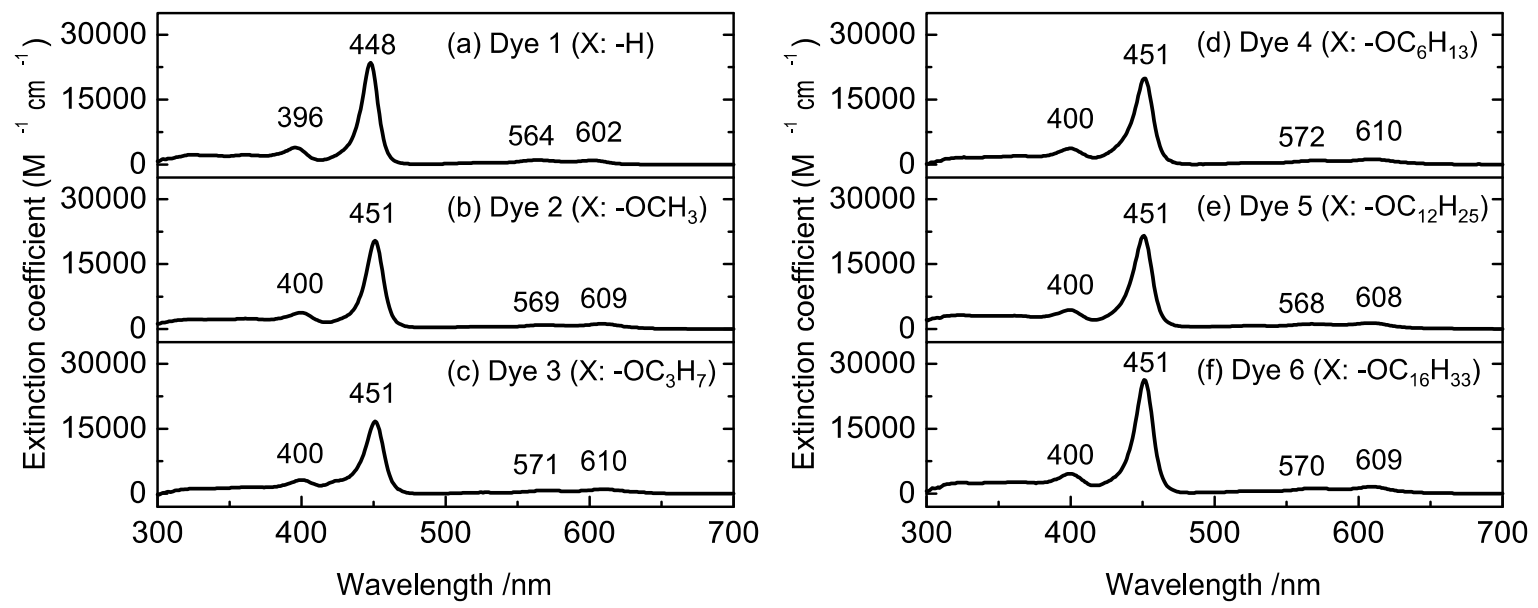

Figure 3. UV-vis spectra of Dyes 1-6 in $\mathrm{CH}_{2} \mathrm{Cl}_{2}$.

The morphology of the prepared samples was determined using FIB-SEM. Figure 4 shows SEM images of the various $\mathrm{KTa}(\mathrm{Zr}) \mathrm{O}_{3}$ photocatalysts modified with Dyes 1-6. All the samples exhibited small particles of various size distributions $(<10 \mathrm{~nm})$ deposited on the surface of larger $\mathrm{KTa}(\mathrm{Zr}) \mathrm{O}_{3}$ particles. These smaller particles appear to be Pt co-catalyst and/or aggregates of porphyrin dyes loaded on the $\mathrm{KTa}(\mathrm{Zr}) \mathrm{O}_{3}$ surface. The particle size of $\mathrm{KTa}(\mathrm{Zr}) \mathrm{O}_{3}$ was approximately $1 \mu \mathrm{m}$, which corresponded well with the results of a laser diffraction analysis of the particle diameters (Figure S11). TEM images of the dye-modified $\mathrm{KTa}(\mathrm{Zr}) \mathrm{O}_{3}$ samples are shown in Figure 5. In all images, the Pt-co-catalysts were observed as black small particles loaded on the larger $\mathrm{KTa}(\mathrm{Zr}) \mathrm{O}_{3}$ particles. The average diameter of Pt-co-catalysts was approximately 2-3 nm. Compared to a TEM image of $\mathrm{KTa}(\mathrm{Zr}) \mathrm{O}_{3}$ without dye modification (Figure S12), the dye-modified $\mathrm{KTa}(\mathrm{Zr}) \mathrm{O}_{3}$ surface seemed to be dappled, which suggested that the porphyrin dyes partially coated the $\mathrm{KTa}(\mathrm{Zr}) \mathrm{O}_{3}$ surface.
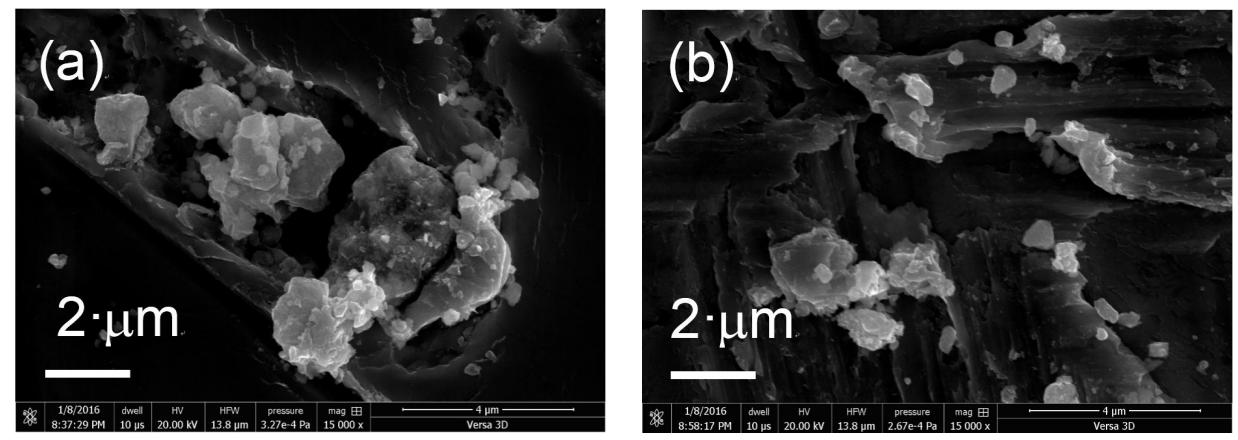

Figure 4. Cont. 

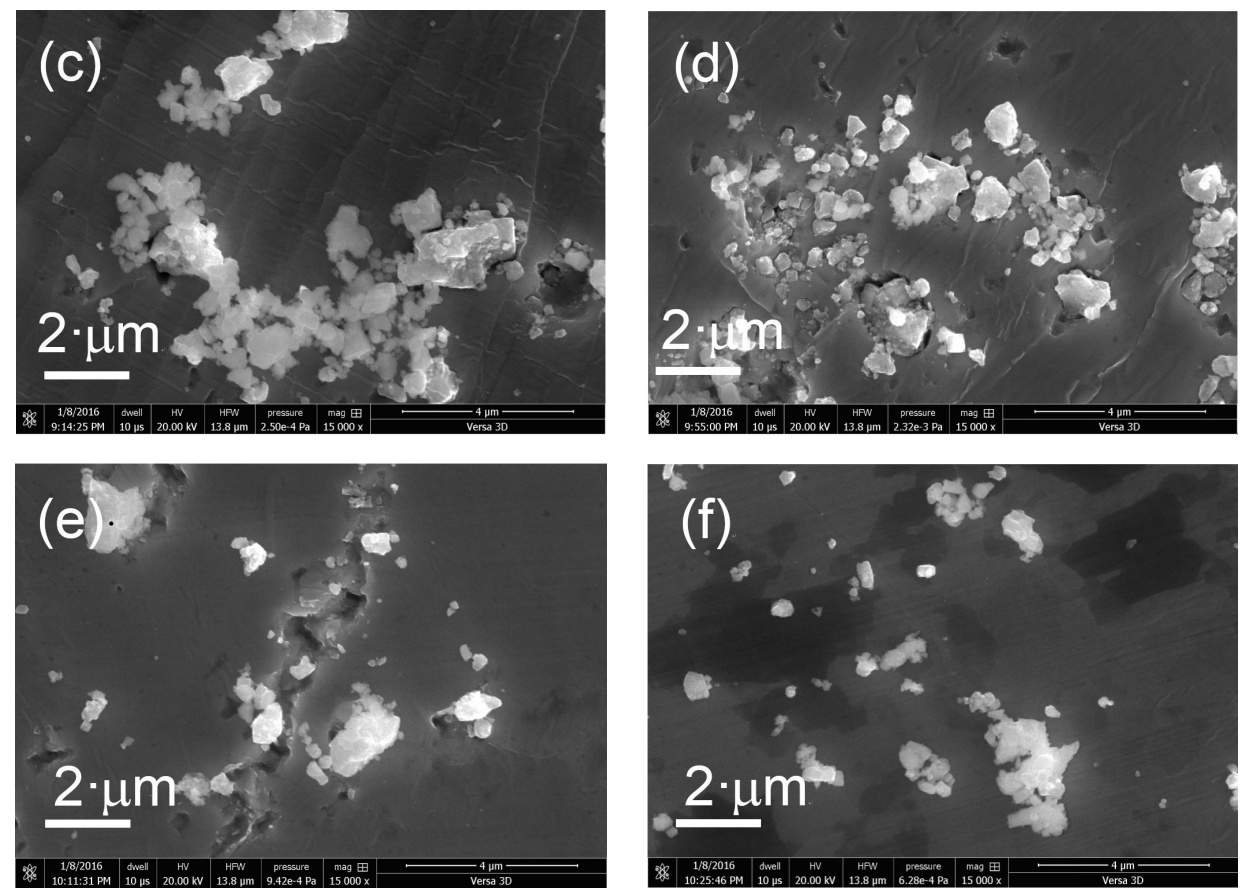

Figure 4. SEM images of $\mathrm{Pt} / \mathrm{KTa}(\mathrm{Zr}) \mathrm{O}_{3}$ modified with (a) Dye 1, (b) Dye 2, (c) Dye 3, (d) Dye 4, (e) Dye 5 and (f) Dye 6.

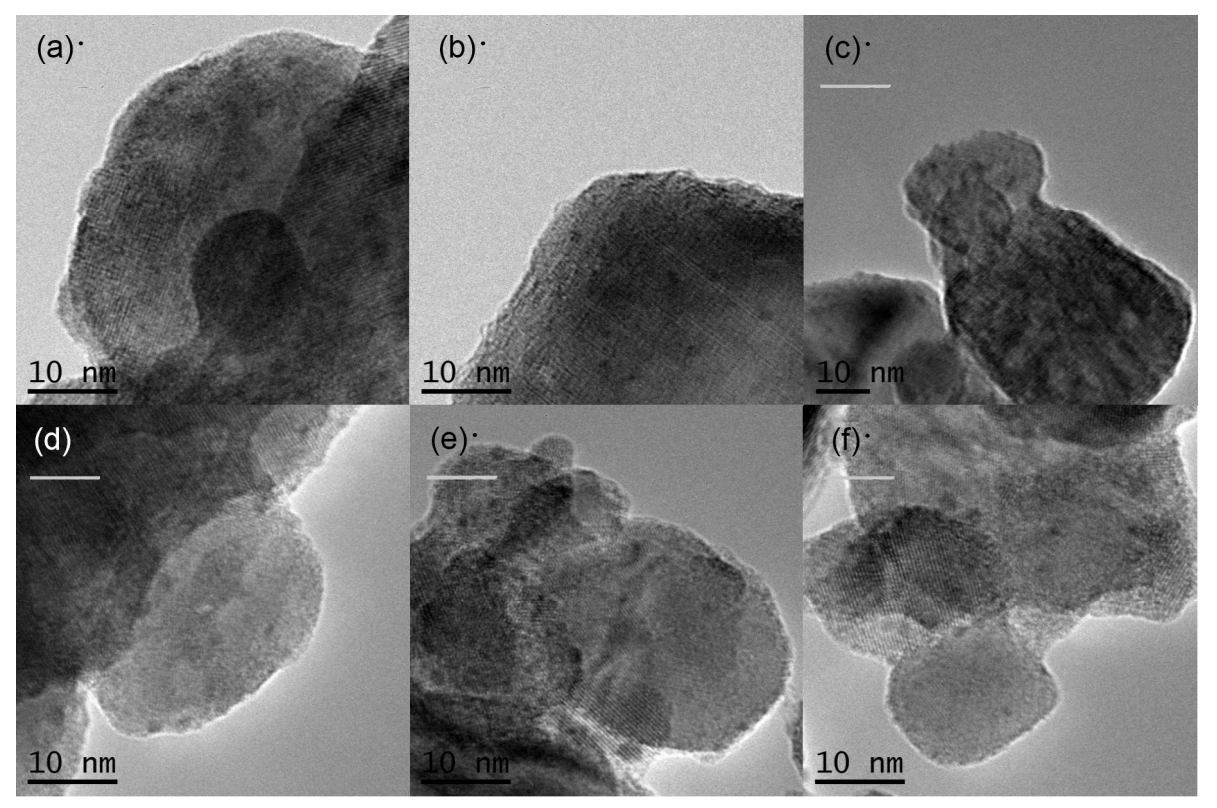

Figure 5. TEM images of Pt/KTa(Zr)O 3 modified with (a) Dye 1, (b) Dye 2, (c) Dye 3, (d) Dye 4, (e) Dye 5 and (f) Dye 6 .

To investigate the aggregation states of Dyes 1-6, UV-vis absorption spectra were measured. Figure 6 shows the UV-vis spectra of the $\mathrm{KTa}(\mathrm{Zr}) \mathrm{O}_{3}$ photocatalyst modified with Dyes 1-6. As shown in Figure $\mathrm{S} 13, \mathrm{KTa}(\mathrm{Zr}) \mathrm{O}_{3}$ absorbed UV light at wavelengths shorter than $350 \mathrm{~nm}$. Broad absorption peaks corresponding to Dyes 1-6 were observed in the visible region from 420 to $700 \mathrm{~nm}$. In comparison with the absorption spectra of the dye solutions (Figure 3), the Soret band absorption peaks of Dyes 1-6 became broad and blue-shifted (6-26 nm), while the Q-band absorption peaks were red-shifted (11-38 nm). This tendency was most obviously observed in the porphyrins bearing longer 
alkoxy chains, such as Dye $\mathbf{5}$ and Dye $\mathbf{6}$. These peak shifts in the absorption spectra occurred as a result of the differences in the aggregation states of the dye compounds. In general, a red-shift is assigned to $J$-aggregations and a blue-shift to $H$-aggregations [22]. The peak-shift of $J$ - and $H$-aggregates are dependent on the differences in transition dipoles: transition dipoles of $J$-aggregates are aligned parallel, while those of $H$-aggregates are aligned perpendicular. In the case of porphyrin derivatives, it has been reported that the aggregation state of the porphyrins can be determined by the shift direction of the Soret band [23,24]. Thus, all porphyrins used in this study appear to form $H$-aggregates on the $\mathrm{KTa}(\mathrm{Zr}) \mathrm{O}_{3}$ surface. Furthermore, the porphyrins that have longer alkoxy chains formed well-developed $H$-aggregates. In comparison with amorphous aggregates, dye aggregates have an advantage when transporting photogenerated charge carriers.
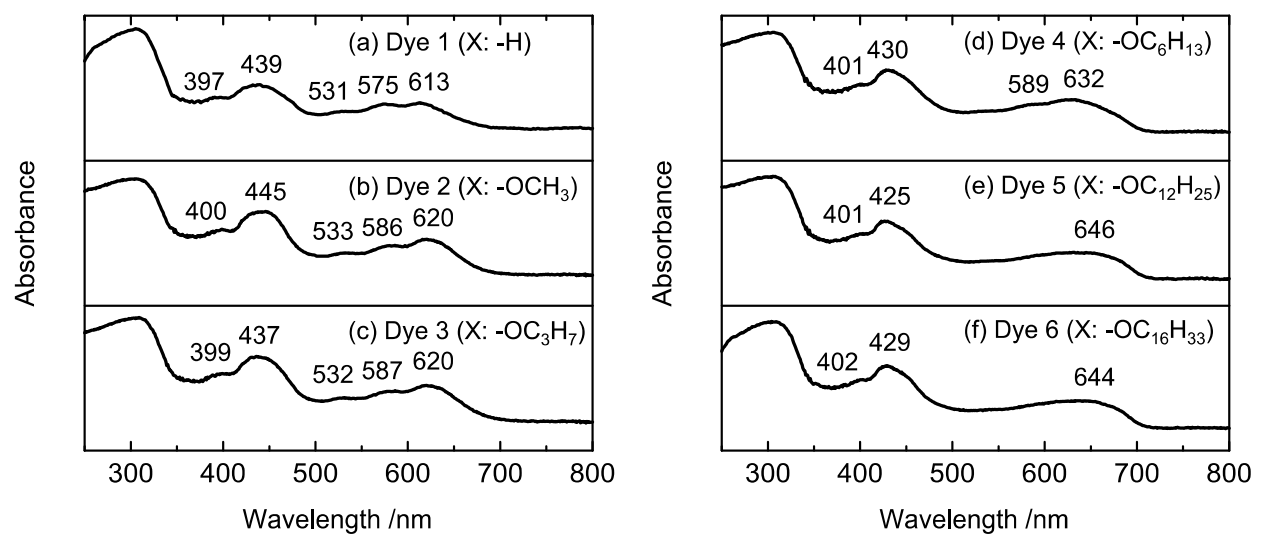

Figure 6. UV-vis absorption spectra of $\mathrm{Pt}\left(0.2\right.$ wt. \%)/porphyrin dye $\left(0.8\right.$ wt. \%)/ $\mathrm{KTa}(\mathrm{Zr}) \mathrm{O}_{3}$.

Figure 7 shows the time course for water splitting on Pt-loaded $\mathrm{KTa}(\mathrm{Zr}) \mathrm{O}_{3}$ modified with Dye 2 . A 1-2 $\mathrm{h}$ induction period was observed after starting photoirradiation, and then the amounts of $\mathrm{H}_{2}$ and $\mathrm{O}_{2}$ formed linearly increased with time. This tendency was observed in all samples (Figure S14). This behavior might be attributed to state changes of the photocatalysts, such as changes in the $\mathrm{Pt}$ co-catalysts' oxidation states or oxidative dye decomposition. The results of a recycle test of the photocatalyst are also shown in Figure 7. The circulating Ar gas was evacuated and exchanged every $5 \mathrm{~h}$. Liner gas formation was observed during each run, and formation rates were slightly decreased over the $15 \mathrm{~h}$ period of the experiment. After the photocatalytic reaction, the amount of Dye 2 remaining on the $\mathrm{KTa}(\mathrm{Zr}) \mathrm{O}_{3}$ surface had decreased to $40 \%$ of the original loading (Figure S15). Although the porphyrin dyes remained in the reaction mixture for at least $15 \mathrm{~h}$ under the photocatalytic water splitting conditions, improving porphyrin stability to allow for their use in prolonged reactions is necessary.

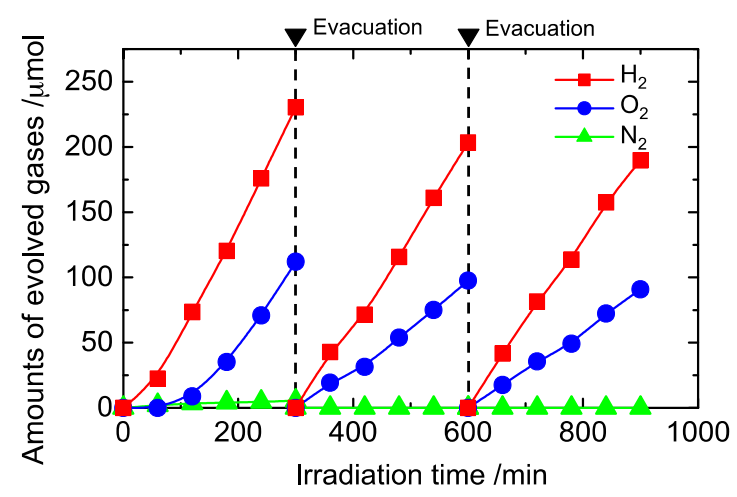

Figure 7. Time course for water splitting on $\mathrm{Pt}\left(0.2\right.$ wt. \%)/Dye 2 (0.8 wt. \%)/ $\mathrm{KTa}(\mathrm{Zr}) \mathrm{O}_{3}$. 
Table 1 shows $\mathrm{H}_{2}$ and $\mathrm{O}_{2}$ formation rates for photocatalytic water splitting on Pt-loaded $\mathrm{KTa}(\mathrm{Zr}) \mathrm{O}_{3}$ modified with Dyes 1-6. In comparison with the result observed for the unmodified Pt-loaded $\mathrm{KTa}(\mathrm{Zr}) \mathrm{O}_{3}$, the photocatalytic activity of the $\mathrm{KTa}(\mathrm{Zr}) \mathrm{O}_{3}$ catalysts was improved by using the porphyrins. In all cases, the gas formation ratio is slightly different from the expected stoichiometry. The errors in the values of formation rates were evaluated using the $\mathrm{Pt} / \mathrm{Dye} 2 / \mathrm{KTa}(\mathrm{Zr}) \mathrm{O}_{3}$ photocatalyst. As shown in Figure S16, the error observed in the oxygen formation rate was larger than that of the hydrogen formation rate. This difference may come from the low sensitivity for oxygen detection in gas chromatography with an Ar carrier and the hole consumption by oxidative dye decomposition. From the viewpoint of dye structure, the porphyrins which have small functional groups (Dye 1 and 2) tended to have a larger positive influence on photocatalytic activity. The porphyrins with small alkoxy groups closely adsorbed onto the $\mathrm{KTa}(\mathrm{Zr}) \mathrm{O}_{3}$ surface; thus, the charge transfer between the photo-excited electrons in $\mathrm{KTa}(\mathrm{Zr}) \mathrm{O}_{3}$ and the porphyrin dyes occurred easily compared with the porphyrins that contained large and bulky alkoxy groups. In our previous study, it was found that efficient electron transfer between the inorganic semiconductor surface and a porphine ring (or its central metal) is important for prolonging the charge separation lifetime and improving the water splitting activity of dye-modified photocatalysts $[17,18]$. Therefore, Dye 2 -modified $\mathrm{KTa}(\mathrm{Zr}) \mathrm{O}_{3}$, containing a methoxy group, showed the highest photocatalytic activity for water splitting in this study. On the contrary, the gas formation rates gradually increased with increasing alkoxy chain length (i.e., from Dye 3 to Dye 6). As mentioned above, the porphyrins with longer alkoxy chains formed well-developed $H$-aggregates on the $\mathrm{KTa}(\mathrm{Zr}) \mathrm{O}_{3}$ surface. The photogenerated electrons (holes) are transported via redox of the porphyrin units; thus, the porphyrin aggregations have great advantages for charge migration because of their overlapping $\pi$ electron clouds. Improvements in the electronic conductivity of the dye aggregates lead to an increase in photogenerated charges that reach the reaction sites on the photocatalyst surface. Therefore, the photocatalytic activity of $\mathrm{KTa}(\mathrm{Zr}) \mathrm{O}_{3}$ was improved by using the porphyrins with longer alkoxy chains. As a result of these two different factors, the modification effects of Dyes 1-6 were observed, as shown in Table 1. Although the porphyrin $H$-aggregates effectively improved the water splitting activity of the $\mathrm{KTa}(\mathrm{Zr}) \mathrm{O}_{3}$ photocatalyst, the charge transfer between the inorganic semiconductor and porphyrin dye interface appears to be the most important factor for achieving efficient water splitting.

Table 1. Photocatalytic activity of porphyrin-modified $\mathrm{KTa}(\mathrm{Zr}) \mathrm{O}_{3}$ for water splitting ${ }^{1}$.

\begin{tabular}{|c|c|c|c|c|}
\hline \multirow{2}{*}{ Dye } & \multirow{2}{*}{$X$} & \multirow{2}{*}{ Amount of dye $/ \mu \mathrm{mol}$} & \multicolumn{2}{|c|}{ Gas Formation Rate $/ \mu \mathrm{mol} \mathrm{h}{ }^{-1}$} \\
\hline & & & $\mathrm{H}_{2}$ & $\mathrm{O}_{2}$ \\
\hline 1 & $-\mathrm{H}$ & 0.57 & 40.0 & 22.7 \\
\hline 2 & $-\mathrm{OCH}_{3}$ & 0.49 & 53.7 & 29.4 \\
\hline 3 & $-\mathrm{OC}_{3} \mathrm{H}_{7}$ & 0.43 & 26.8 & 12.8 \\
\hline 4 & $-\mathrm{OC}_{6} \mathrm{H}_{13}$ & 0.36 & 30.3 & 14.9 \\
\hline 5 & $-\mathrm{OC}_{12} \mathrm{H}_{25}$ & 0.28 & 34.7 & 19.1 \\
\hline 6 & $-\mathrm{OC}_{16} \mathrm{H}_{33}$ & 0.24 & 43.1 & 23.9 \\
\hline None & - & 0.0 & 7.8 & 4.6 \\
\hline
\end{tabular}

1 Photocatalyst: Pt (0.2 wt. \%)/Dye (0.8 wt. \%)/KTa(Zr)O 3 (50 mg), Light: Xe lamp (Full arc, $620 \mathrm{~mW})$, Reaction time: $5 \mathrm{~h}$.

\section{Materials and Methods}

\subsection{Photocatalyst Preparation}

\subsubsection{Zr-doped $\mathrm{KTaO}_{3}$ Preparation}

All reagents were used without further purification. $\mathrm{KTa}(\mathrm{Zr}) \mathrm{O}_{3}$ was synthesized by a solid-state reaction method, as reported elsewhere [17]. $\mathrm{Ta}_{2} \mathrm{O}_{5}$ (Kojundo Chemical Lab., Tokyo, Japan), $\mathrm{K}_{2} \mathrm{CO}_{3}$ (Wako, Osaka, Japan) and $\mathrm{ZrO}\left(\mathrm{NO}_{3}\right)_{2} \cdot 2 \mathrm{H}_{2} \mathrm{O}$ (Nacalai tesque, Kyoto, Japan) were mixed in pure water. 
The water was evaporated to dryness with stirring. The resultant mixture was ground in an alumina mortar for $10 \mathrm{~min}$ and calcined in an alumina crucible at $900{ }^{\circ} \mathrm{C}$ for $10 \mathrm{~h}$ under an air atmosphere. The crystal structure of the resultant sample was determined by using powder X-ray diffraction (Figure S17).

\subsubsection{Porphyrin Dye Synthesis}

The 5,10,15,20-Tetraphenylporphyrin (Tokyo Chemical Industry Co., Ltd., Tokyo, Japan) was purchased and used without further purification. The 5,10,15,20-Tetrakis(4-methoxyphenyl)porphyrin and $4,4^{\prime}, 4^{\prime \prime}, 4^{\prime \prime \prime}$-(porphyrin-5,10,15,20-tetrayl) tetraphenol were synthesized according to literature methods [25]. A mixture of 4, $4^{\prime}, 4^{\prime \prime}, 4^{\prime \prime \prime}$-(porphyrin-5,10,15,20-tetrayl)tetraphenol (350 mg, $0.516 \mathrm{mmol}$ ), $\mathrm{K}_{2} \mathrm{CO}_{3}$ (Tokyo Chemical Industry Co., Ltd., Tokyo, Japan) (1.43 g, $10.33 \mathrm{mmol}$ ), 18-crown-6 (Tokyo Chemical Industry Co., Ltd., Tokyo, Japan) (0.273 g, $1.034 \mathrm{mmol})$ and DMF (Sigma-Aldrich Co. LLC.,Tokyo, Japan) $(40 \mathrm{~mL})$ was stirred at $60{ }^{\circ} \mathrm{C}$ under nitrogen atmosphere. After $15 \mathrm{~min}$, alkyl bromide (Tokyo Chemical Industry Co. Ltd., Tokyo, Japan) $(10.33 \mathrm{mmol})$ was added in one portion, and the reaction was stirred for additional $5 \mathrm{~h}$ at reflux under a nitrogen atmosphere. The reaction was quenched with water, and the resultant precipitate was filtered. Silica gel chromatography (KANTO Kieselgel Si 60 (40-63 mm) , Kanto Chemical Co., Inc., Tokyo, Japan) using $\mathrm{CH}_{2} \mathrm{Cl}_{2}$ (Kanto Chemical Co. Inc., Tokyo, Japan) as the eluent gave the desired porphyrin. The porphyrin chromium chloride complexes were synthesized according to methods given in the literature [26] as follows: porphyrin $(1 \mathrm{mmol})$ was dissolved in dry DMF and heated to reflux. To this mixture was added an excess amount of $\mathrm{CrCl}_{3}$ (Sigma-Aldrich Co. LLC., Tokyo, Japan) (4 mmol). After UV-vis measurements showed the complete disappearance of the free-base porphyrin, the reaction mixture was poured into ice water. The green-colored precipitate was then filtered and washed with water. Silica gel column chromatography using $\mathrm{CHCl}_{3}-\mathrm{MeOH}$ (Kanto Chemical Co., Inc., Tokyo, Japan)was used to purify the product. Further details of the syntheses are summarized in Supplementary Materials.

\subsubsection{Preparation of Porphyrin-Modified $\mathrm{KTa}(\mathrm{Zr}) \mathrm{O}_{3}$ Photocatalysts}

An "evaporation to dryness" method was employed to modify the $\mathrm{KTa}(\mathrm{Zr}) \mathrm{O}_{3}$ surface using pyridine as the solvent at $130{ }^{\circ} \mathrm{C}$. In this study, the dye amount was unified at $0.8 \mathrm{wt}$. \%. For loading the $\mathrm{Pt}$ co-catalyst onto the porphyrin $/ \mathrm{KTa}(\mathrm{Zr}) \mathrm{O}_{3}$, the "evaporation to dryness" method was also used using water as the solvent. $\mathrm{Pt}\left(\mathrm{NH}_{3}\right)_{4}\left(\mathrm{NO}_{3}\right)_{2}$ (Sigma-Aldrich Co. LLC., Tokyo, Japan) was used as the $\mathrm{Pt}$ co-catalyst precursor. The loading amount of the Pt co-catalyst was $0.2 \mathrm{wt}$ \% $\%$

\subsection{Photocatalytic Water Splitting Reaction}

The photocatalytic activity for water splitting was evaluated using a closed-circulation-type glass reactor with a dead volume of $450 \mathrm{~mL}$ (Figure S18). The catalyst (50 mg) was dispersed in $30 \mathrm{~mL}$ of distilled water. A quartz reaction cell was illuminated by a $300 \mathrm{~W}$ Xe lamp (Cermax, PE300BUV, Excelitas Technologies Corp., Waltham, MA USA). The spectrum of the excitation light source is shown in Supplementary Materials (Figure S19). Argon gas (10.67 kPa) was used as a carrier gas in the reactor. Gas leakage was checked for $1 \mathrm{~h}$ in the dark prior to reaction initiation. Gas evolution amounts were measured using a gas chromatograph (GC-8A, Shimadzu Corp., Kyoto, Japan).

\subsection{Photocatalyst Characterization}

TEM (JEM-2100TI, JEOL, Tokyo, Japan) and FIB-SEM (Versa 3D HiVac, FEI, Hillsboro, OH, USA) were used to observe the surface morphology of the dye-modified $\mathrm{KTa}(\mathrm{Zr}) \mathrm{O}_{3}$ samples. UV-vis absorption spectra of the porphyrin-pyridine solutions and the dye-modified $\mathrm{KTa}(\mathrm{Zr}) \mathrm{O}_{3}$ were measured using a spectrophotometer (U-3310, Hitachi, Tokyo, Japan). The ${ }^{1} \mathrm{H}$ and ${ }^{13} \mathrm{C}$ NMR spectra were recorded on a Bruker AVANCE-400 NMR spectrometer $(400 \mathrm{MHz})$. The chemical shifts are reported as $\delta$ values (ppm) relative to internal tetramethylsilane. The coupling constants $(\mathrm{J})$ are given in hertz. Absorption spectra were recorded on a Shimadzu UV-3600 spectrometer. Mass spectra were 
recorded on either a Bruker Autoflex mass spectrometer or a JEOL JMS-T100LP mass spectrometer. Silica gel 60 F254 (Merck, Frankfurt, Germany) was used for analytical thin-layer chromatography. Cyclic voltammetry was performed using a three-electrode cell, with a glassy carbon electrode as the working electrode, a platinum $(\mathrm{Pt})$ wire as the counter electrode and $0.01 \mathrm{M} \mathrm{Ag} / \mathrm{AgNO} 3$ in $0.1 \mathrm{M}$ tetrabutylammonium perchlorate as the reference electrode. An X-ray diffractometer (RINT-2500, Rigaku, Tokyo, Japan) was used to determine the crystal structures of the samples.

\section{Conclusions}

The effect of porphyrin molecular structure on the water splitting activity of porphyrin-modified $\mathrm{KTa}(\mathrm{Zr}) \mathrm{O}_{3}$ was investigated in this study. Although the surface morphologies of the Pt/porphyrin dye $/ \mathrm{KTa}(\mathrm{Zr}) \mathrm{O}_{3}$ photocatalysts were similar in SEM and TEM observations, UV-vis spectra indicated that the porphyrins with long alkoxy chains formed well-developed $H$-aggregates on the $\mathrm{KTa}(\mathrm{Zr}) \mathrm{O}_{3}$ surface. The photocatalytic activity of Pt-loaded $\mathrm{KTa}(\mathrm{Zr}) \mathrm{O}_{3}$ was improved by the porphyrins with longer alkoxy chains because of the improvement in the charge migration between the porphyrin dye molecules. Although the charge transfer between the inorganic semiconductor and porphyrin dye interface is important for water splitting, this study revealed that the formation of $H$-aggregates was more effective in improving the activity of porphyrin-modified photocatalysts.

Supplementary Materials: The following are available online at www.mdpi.com/2073-4344/6/3/42/s1: Figure S1, S3, S5 and S7: ${ }^{1} \mathrm{H}$ NMR spectra of the precursor compounds of Dyes 3, 4, 5 and 6; Figure S2, S4, S6 and S8: ${ }^{13} \mathrm{C}$ NMR spectra of the precursor compounds of Dyes 3, 4, 5 and 6; Figure S9: CSI-MS spectra of Dyes 1-6; Figure S10: Cyclic voltammograms of Dyes 1-6; Figure S11: Particle size distribution of $\mathrm{KTa}(\mathrm{Zr}) \mathrm{O}_{3}$ measured using a laser diffraction particle size analyzer; Figure S12: TEM image of $\mathrm{KTa}(\mathrm{Zr}) \mathrm{O}_{3}$; Figure S13: UV-vis spectrum of $\mathrm{KTa}(\mathrm{Zr}) \mathrm{O}_{3}$; Figure S14: Time course of water splitting over Pt-loaded $\mathrm{KTa}_{2}(\mathrm{Zr}) \mathrm{O}_{3}$ modified with Dyes 1-6; Figure S15: UV-vis absorption spectra of Dye 2 present on $\mathrm{KTa}(\mathrm{Zr}) \mathrm{O}_{3}$ before and after the photocatalytic reaction; Figure S16: Gas formation rates of water splitting on Pt/Dye 2/KTa(Zr)O ${ }_{3}$; Figure S17: XRD pattern of $\mathrm{KTa}(\mathrm{Zr}) \mathrm{O}_{3}$; Figure S18: Schematic image of a closed-circulation type glass reactor; Figure S19: Spectrum of the Xe lamp used in this study.

Acknowledgments: This work was supported by a Grant-in-Aid for Exploratory Research (No. 26630497) from the Ministry of Education, Culture, Sports, Science, and Technology (MEXT) of Japan.

Author Contributions: H.H., M.W., S.I., and T.I. conceived and designed the experiments; H.H., K.H., M.W., and R.K. performed the experiments; H.H. and M.W. analyzed the data and wrote the paper.

Conflicts of Interest: The authors declare no conflict of interest.

\section{Abbreviations}

The following abbreviations are used in this manuscript:

NADPH Nicotinamide adenine dinucleotide phosphate (reduced form)

$\mathrm{NADP}^{+} \quad$ Nicotinamide adenine dinucleotide phosphate (oxidized form)

TEM Transmission electron microscopy

NMR Nuclear Magnetic Resonance

CSI-MS Cold-spray ionization mass spectroscopy

FIB-SEM focused ion beam-scanning electron microscopy

DMF N,N-dimethylformamide

SEM Scanning electron microscopy

\section{References}

1. Loll, B.; Kern, J.; Saenger, W.; Zouni, A.; Biesiadka, J. Towards complete cofactor arrangement in the $3.0 \AA$ resolution structure of photosystem II. Nature 2005, 438, 1040-1044. [CrossRef] [PubMed]

2. May, M.M.; Lewerenz, H.-J.; Lackner, D.; Dimroth, F.; Hannappel, T. Efficient direct solar-to-hydrogen conversion by in situ interface transformation of a tandem structure. Nat. Commun. 2015, 6, 8286. [CrossRef] [PubMed] 
3. Peltier, G.; Tolleter, D.; Billon, E.; Cournac, L. Auxiliary electron transport pathways in chloroplasts of microalgae. Photosynth. Res. 2010, 106, 19-31. [CrossRef] [PubMed]

4. Jin, J.; Yu, J.; Guo, D.; Cui, C.; Ho, W. A hierarchical Z-scheme CdS-WO 3 photocatalyst with enhanced $\mathrm{CO}_{2}$ reduction activity. Small 2015, 16, 5262-5271. [CrossRef] [PubMed]

5. Zhou, P.; Yu, J.; Jaroniec, M. All-solid-state Z-scheme photocatalytic systems. Adv. Mater. 2014, 26, $4920-4935$.

6. Kato, H.; Hori, M.; Konta, R.; Shimodaira, Y.; Kudo, A. Construction of Z-scheme type heterogeneous photocatalysis systems for water splitting into $\mathrm{H}_{2}$ and $\mathrm{O}_{2}$ under visible light irradiation. Chem. Lett. 2004, 33, 1348-1349. [CrossRef]

7. Sasaki, Y.; Iwase, A.; Kato, H.; Kudo, A. The effect of co-catalyst for Z-scheme photocatalysis systems with an $\mathrm{Fe}^{3+} / \mathrm{Fe}^{2+}$ electron mediator on overall water splitting under visible light irradiation. J. Catal. 2008, 259, 133-137. [CrossRef]

8. Abe, R.; Takata, T.; Sugihara, H.; Domen, K. Photocatalytic overall water splitting under visible light by TaON and $\mathrm{WO}_{3}$ with an $\mathrm{IO}_{3}^{-} / \mathrm{I}^{-}$shuttle redox mediator. Chem. Commun. 2005, 3829-3831. [CrossRef] [PubMed]

9. Higashi, M.; Abe, R.; Ishikawa, A.; Takata, T.; Ohtani, B.; Domen, K. Z-scheme overall water splitting on modified-TaON photocatalysts under visible light $(\lambda<500 \mathrm{~nm})$. Chem. Lett. 2008, 37, 138-139.

10. Tabata, M.; Maeda, K.; Higashi, M.; Lu, D.; Takata, T.; Abe, R.; Domen, K. Modified $\mathrm{Ta}_{3} \mathrm{~N}_{5}$ powder as a photocatalyst for $\mathrm{O}_{2}$ evolution in a two-step water splitting system with an iodate/iodide shuttle redox mediator under visible light. Langmuir 2010, 26, 9161-9165. [CrossRef] [PubMed]

11. Maeda, K.; Abe, R.; Domen, K. Role and function of ruthenium species as promoters with TaON-based photocatalysts for oxygen evolution in two-step water splitting under visible light. J. Phys. Chem. C 2011, 115, 3057-3564. [CrossRef]

12. Matoba, T.; Maeda, K.; Domen, K. Activation of $\mathrm{BaTaO}_{2} \mathrm{~N}$ photocatalyst for enhanced non-sacrificial hydrogen evolution from water under visible light by forming a solid solution with $\mathrm{BaZrO}_{3}$. Chem. Eur. J. 2011, 17, 14731-14735. [CrossRef] [PubMed]

13. Maeda, K.; Lu, D.; Domen, K. Solar-Driven Z-scheme water splitting using modified $\mathrm{BaZrO}_{3}-\mathrm{BaTaO}_{2} \mathrm{~N}$ solid solutions as photocatalysts. ACS Catal. 2013, 3, 1026-1033. [CrossRef]

14. Ma, S.S.K.; Maeda, K.; Hisatomi, T.; Tabata, M.; Kudo, A.; Domen, K. A redox-mediator-free solar-driven Z-Scheme water-splitting system consisting of modified $\mathrm{Ta}_{3} \mathrm{~N}_{5}$ as an oxygen-evolution photocatalyst. Chem. Eur. J. 2013, 19, 7480-7486. [CrossRef] [PubMed]

15. Iwase, A.; Ng, Y.H.; Ishiguro, Y.; Kudo, A.; Amal, R. Reduced graphene oxide as a solid-state electron mediator in Z-scheme photocatalytic water splitting under visible light. J. Am. Chem. Soc. 2011, 133, 11054-11057. [CrossRef] [PubMed]

16. Hagiwara, H.; Inoue, T.; Ida, S.; Ishihara, T. Long-time charge separation in porphyrin $/ \mathrm{KTa}(\mathrm{Zr}) \mathrm{O}_{3}$ as water splitting photocatalyst. Phys. Chem. Chem. Phys. 2011, 13, 18031-18037. [CrossRef] [PubMed]

17. Hagiwara, H.; Inoue, T.; Kaneko, K. Ishihara, Charge-transfer mechanism in $\mathrm{Pt} / \mathrm{KTa}(\mathrm{Zr}) \mathrm{O}_{3}$ photocatalysts modified with porphyrinoids for water splitting. Chem. Eur. J. 2009, 15, 12862-12870. [CrossRef] [PubMed]

18. Hagiwara, H.; Ono, N.; Inoue, T.; Matsumoto, H.; Ishihara, T. Dye-sensitizer effects on a Pt/KTa( $\mathrm{Zr}) \mathrm{O}_{3}$ catalyst for the photocatalytic splitting of water. Angew. Chem. Int. Ed. 2006, 45, 1420-1422. [CrossRef] [PubMed]

19. Hagiwara, H.; Nagatomo, M.; Seto, C.; Ida, S.; Ishihara, T. Dye-modification effects on water splitting activity of GaN:ZnO photocatalyst. J. Photochem. Photobio. A 2013, 272, 41-48. [CrossRef]

20. Hagiwara, H.; Nagatomo, M.; Seto, C.; Ida, S.; Ishihara, T. Dye modification effects on TaON for photocatalytic hydrogen production from water. Catalysts 2013, 3, 614-624. [CrossRef]

21. Rutherford, A.W.; Faller, P. Photosystem II: Evolutionary perspectives. Phil. Trans. R. Soc. Lond. B 2003, 358, 245-253. [CrossRef] [PubMed]

22. Würthner, F.; Kaiser, T.E.; Saha-Möller, C.R. J-aggregates: From serendipitous discovery to supramolecular engineering of functional dye materials. Angew. Chem. Int. Ed. 2011, 50, 3376. [CrossRef] [PubMed]

23. Kano, K.; Fukada, K.; Wakami, H.; Nishiyabu, R.; Pasternack, R.F. Factors influencing self-aggregation tendencies of cationic porphyrins in aqueous solution. J. Am. Chem. Soc. 2000, 122, 7494-7502. [CrossRef]

24. Král, V.; Schmidtchem, F.P.; Lang, K.; Berger, M. Anion-controlled assembly of porphyrin-bicyclic guanidine conjugates. Org. Lett. 2002, 1, 51-54. [CrossRef] 
25. Miyajima, N.; Furuta, N.; Wakunami, S.; Mizutani, T. Functionalization of silica surface by tetrahydroxyporphyrin via Si-O linkages. Bull. Chem. Soc. Jpn. 2011, 84, 794-801.

26. Chen, A.P.; Chisholm, M.H.; Gallucci, J.C.; Zhang, X.; Zhou, Z. Binding of propylene oxide to porphyrin- and Salen-M(III) cations, where M = Al, Ga, Cr, and Co. Inorg. Chem. 2005, 44, 2588-2595. [CrossRef] [PubMed]

(c) 2016 by the authors; licensee MDPI, Basel, Switzerland. This article is an open access article distributed under the terms and conditions of the Creative Commons by Attribution (CC-BY) license (http:/ / creativecommons.org/licenses/by/4.0/). 